\title{
Preparing Agile Transformation: A Framework for Assessment of the Organizational Culture Readiness
}

\author{
Petra Barthelmess \\ Zurich University of Applied Sciences
}

\author{
Albena Björck \\ Zurich University of Applied Sciences \\ Emanuel Gysin \\ PwC \\ Jeremy Dela Cruz \\ Zurich University of Applied Sciences
}

\begin{abstract}
With disruptions reshaping the global economy, companies need to find a way to embrace constant change. Recently, "becoming Agile" has been the motto of organizational change. However, more than half of all organizations have at least one agile transformation project fail, often due to an unsuitable organizational culture. This research provides a framework to assesses organizational culture's readiness for Agile, by integrating existing models in the areas of change management, organizational, and Agile culture which may help companies to identify possible deficiencies in the organizational culture that can then be targeted prior to the Agile transformation.
\end{abstract}

Keywords: organizational culture, Agile organization, readiness assessment

\section{INTRODUCTION}

Increasing volatility and uncertainty of the markets, rapid technological innovations and new competitors that disrupt the value chain in the contemporary business world force companies to find new ways to embrace constant and often unpredictable change (Hemerling et al., 2015; Wessel, 2017). From an organizational point of view, being Agile has become increasingly popular among companies across various industries. Empirical evidence shows that Agile organizations operating in environments with high pressure outperform their non-Agile counterparts, and can keep this high-performance long-term, in particular, by achieving better customer focus, faster product launches, higher growth in revenue, lower costs, and more involved employees (Aghina et al., 2018; Bazigos, et al., 2015). Therefore, it is not surprising that in a survey conducted with 2,500 business leaders, $75 \%$ stated that organizational agility is a top-three priority for their organization (Aghina et al., 2018). 
Even though many organizations want to be more Agile, more than half of them experience at least one of their Agile projects fail (CollabNet VersionOne, 2019, p. 11). The most often named reason for those failures is the unfitting organizational culture for Agile transformations (CollabNet VersionOne, 2019, p. 12). This is not surprising as business leaders focus too strongly on changing strategies, policies, and processes while neglecting the underlying corporate culture and its compatibility with the new Agile organization (Groysberg et al., 2018; Schwartz, 2018). Whereas the strategy of an organization provides clarity and focus on what to do, in a transitional process, culture the values and beliefs that guide and support this activity (Groysberg et al., 2018). The one-sided focus on strategy and processes might be explained by the fact that culture is harder to grasp as well as more difficult to change (Groysberg et al., 2018; Handscomb et al., 2018).

This research aims to investigate how companies can assess their organizational culture with regard to its readiness for Agile. To answer the research question, a framework has been developed and tested with several companies.

\section{LITERATURE REVIEW}

\section{Agile Organization}

Numerous researchers and consultants have proposed different definitions of organizational agility. Plant and Murrell (1997) define an Agile organization from a systemic perspective as "a concept of systems flexibility, support, and control...integrated into all aspects of the organization's value chain...allowing the organization to continually reinvent itself and continually compete in a global marketplace." (pp. 26). Sherehiy (2007) states that agility is a strategic capability to adapt rapidly and flexibly to unanticipated and sudden changes in the market.

The new Agile organizational paradigm is, according to Darino et al. (2019), “...made up of a network of teams within a people-centered culture that features...fast decision cycles enabled by technology and guided by a powerful common purpose..." (pp. 2). Consequently, Agile organizations combine stability with dynamism and therefore are very suitable for a "...volatile, uncertain, complex, and ambiguous..." environment (Darino et al., 2019, pp. 2). Further recurring themes closely connected to the term agility are innovation (Plant \& Murrell, 1997, Rigby et al., 2016), dynamic capabilities (Verdu \& Gomez-Gras, 2009, Teece et al., 2016), the abolishment of traditional hierarchies and top-down decision-making processes (Darino et al., 2019), fast market responsiveness (Sherehiy et al. 2007), high operational speed (Dyer \& Schafer, 2003), and organizational change and learning (Najrani, 2016).

The term Agile and the idea behind it was established in a manifesto written about software development by Beck, et al. (2001a and b). In this manifesto they defined four Agile values and twelve Agile principles. For example, the values embrace the importance of people and relationships over processes, software over documentation, collaboration over contract negotiation and responding to change over following a plan (Beck et al., 2001a). Even though those values and principles have been defined for software development, the concept it holds can be used for other industries. Rigby, Sutherland, and Takeuchi (2016) state that Agile is not a panacea and narrow down the term by discussing favorable and unfavorable conditions for Agile approaches. For example, Agile is meaningful when customer requirements are likely to change, and creative breakthroughs are important, and less practicable in case of routine operations and stable and predictable market conditions.

Summarizing existing research, surveys, and business project experiences, Anghina et al. (2018) have identified consistent characteristics of agile organizations, across industries. The so-called five categories include 23 practices for organizational agility. When these are compared with the definitions of Agile following characteristics emerge (see Table 1 below): 


\section{TABLE 1}

\section{CHARACTERISTICS OF AGILE ORGANIZATIONS AND ORGANIZATIONAL AGILITY PRACTICES}

\begin{tabular}{|c|c|c|}
\hline Dimensions & Category & Organizational-agility practice \\
\hline Strategy & $\begin{array}{l}\text { North Start embodied } \\
\text { across the organization }\end{array}$ & $\begin{array}{l}\text { Shared purpose and vision } \\
\text { Sensing and seizing opportunities } \\
\text { Flexible resource allocation } \\
\text { Actionable strategic guidance }\end{array}$ \\
\hline Structure & $\begin{array}{l}\text { Network of empowered } \\
\text { teams }\end{array}$ & $\begin{array}{l}\text { Clear, flat structure } \\
\text { Clear accountable roles } \\
\text { Hands-on governance } \\
\text { Robust communities of practice } \\
\text { Active partnerships and ecosystem } \\
\text { Open physical and virtual environment } \\
\text { Fit-for-purpose accountable cells }\end{array}$ \\
\hline Process & $\begin{array}{l}\text { Rapid decision and } \\
\text { learning cycles }\end{array}$ & $\begin{array}{l}\text { Rapid iteration and experimentation } \\
\text { Standardized ways of working } \\
\text { Performance orientation } \\
\text { Information transparency } \\
\text { Continuous learning } \\
\text { Action-oriented decision making }\end{array}$ \\
\hline People & $\begin{array}{l}\text { Dynamic people model } \\
\text { that ignites passion }\end{array}$ & $\begin{array}{l}\text { Cohesive community } \\
\text { Shared and servant leadership } \\
\text { Entrepreneurial drive } \\
\text { Role mobility }\end{array}$ \\
\hline Technology & $\begin{array}{l}\text { Next generation } \\
\text { enabling technology }\end{array}$ & $\begin{array}{l}\text { Evolving technology architecture, systems, and tools } \\
\text { Next-generation technology development and delivery } \\
\text { practices }\end{array}$ \\
\hline
\end{tabular}

Source: Aghina, Ahlback, De Smet, Lurie, Muraka and Handscomb, 2018, pp. 4

\section{Organizational Culture}

Culture, in general, has been defined as "both a dynamic phenomenon that surrounds us at all times, being constantly enacted and created by our interactions with others and shaped by leadership behavior, and a set of structures, routines, rules, and norms that guide and constrain behavior." (Schein, 2004, p. 1). Culture in this sense is:

- What defines us as a group, like a "collective level of mental programming" (Hofstede, 2003, p. 22).

- What defines the implicit social order of a group that forms attitudes and behaviors in extensive and enduring ways (Groysberg et al., 2018).

- "What is being shared with people that have gone and keep going through the same mental learning processes" (Hofstede, 2003, p. 24).

For Schein (1985) a primary issue in competitiveness and organizational adaptability is that of organizational culture. According to Schein (2004), organizational culture can be analyzed on three different levels, depending on the visibility of culture for the observer. Most visible are the so-called Artefacts, which are cultural manifestations that can be seen. Then there are the Espoused Beliefs and Values, which are openly communicated norms and rules of behavior - a shared understanding of what is right and what is wrong of an organization. On the deepest level, one finds the Underlying Assumptions, which stand at the heart of that organization. They are either considered sacrosanct or are so deeply rooted that most people are not even aware of them. Challenging or questioning such Underlying Assumptions 
triggers anxiety and defensiveness among the members of that particular culture, which needs to be considered when trying to change the organizational culture.

Schein's socio-technical model of organizational innovation positions the underlying cultural assumptions as the key factor that influences the state of information technology, organizational structure, and process, and finally organizational innovation (Schein, 1994). His thesis has been confirmed by Plant and Murrell (1987) who place implicit beliefs, values, and assumptions at the center to analyze the innovation and change capability of an organization. And in this sense, we focus our inquiry on this deepest, most implicit, and fundamental level of cultural manifestation.

\section{Agile Organizational Culture: Pre-Existing Frameworks}

In the literature, there is a growing interest in investigating the relationships between organizational culture and Agile organization, but research on details that support a systematic development of Agile culture are rare (Küpper et al. 2017). For the purpose of this study, we analyzed following organizational culture concepts that include elements of Agile corporate culture:

- Rising's Agile Mindset

- Cameron and Quinn's Competing Values Framework

- The Denison's Model for Diagnosing Organizational Culture

- Joël Krapf's Agile Culture Check

- Agile Business Consortium's Agile Culture Development Matrix

All concepts and models contribute to the design of our framework and formulation of our questionnaire. Following, the concepts are introduced, based on the order from broad to more detailed.

In the context of going Agile, Rising (2016) argues that a growth mindset is necessary and that a fixed mindset would only hinder an Agile transformation. For him, the growth mindset can also be named Agile Mindset and is characterized by a motivation to learn, challenges are to be embraced because they offer growth opportunities, failures are an important source for information, through continuous efforts one can achieve mastery and challenges are to be met with resilience.

According to Campbell, Bownas, Peterson, and Dunnette's Competing Values Framework, there are 39 indicators of organizational effectiveness (Campbell et al., 1974) which can be categorized into four main clusters, presented along two axes: Flexibility versus Focus, and Internal versus External (Quinn \& Rohrbaugh, 1983). Along these axes Cameron and Quinn (2006) defined the four fundamental values and corresponding culture types of an organization:

(1) The collaborative (clan) culture is flexible and internal. It focuses on shared values and goals, participation, commitment, and teamwork thus making an effort to establish a positive internal climate that encourages employees to express suggestions on how to improve the performance of the organization.

(2) The creative (adhocracy) culture is flexible and external. It focuses on innovation, entrepreneurship, and creativity. The power in this culture is not centralized; instead, it is moved to the individual or the team where it is needed the most to accomplish a task.

(3) The control (hierarchy) culture is focused and internal. It is depicted by a highly structured way of working where the procedures direct employees what to do and the main tasks of leaders are to organize and coordinate. The goal of the organization is to create stability, predictability, and efficiency by having strict processes, rules, and policies implemented.

(4) The competitive (market) culture is focused and external. It focuses on transactions with external stakeholders (e.g., suppliers, customers) to achieve the core values of competitiveness and productivity. Internally, the organization is held together by the shared emphasis on the common goal rather than defined rules, procedures, and centralized decisions (Cameron \& Quinn, 2006, pp. 38-45).

According to Iivari (2010, p. 208 seqq.), the dimension Create (adhocracy culture) represents organizational agility the best, as it is flexible and has an external focus. Conversely, they consider the dimension Control (hierarchy culture) as least suitable for Agile. Aghina, et al. (2015) disagree with this 
assertion as they state that Agile is not only about being flexible but also about being stable. According to them, truly Agile organizations exhibit not only dynamism but also stability by having a strong backbone. This can be a defined organizational structure, a practice in who makes decisions, and how decisions are made, or standardized languages and performance metrics implemented across all teams (Aghina et al., 2015). In light of this controversy, we have decided to include each one of the four dimensions as valuable for Agile.

Denison et al. (2006) took the four dimensions of the Cameron and Quinn's Competing Values Framework, and renamed them in Collaborate to Involvement, Create to Adaptability, Control to Consistency, Compete to Mission. In every dimension three subcategories were defined:

(1) Collaborate to Involvement: Develops organizational capability, builds team orientation, empowers people;

(2) Create to Adaptability: Creates change, emphasizes customer focus, and promotes organizational learning;

(3) Control to Consistency: Defines core values, works to reach agreement, and manages coordination and integration;

(4) Compete to Mission: Defines strategic direction and intent, defines goals and objectives, and creates shared vision.

The framework has been validated by a survey with a sample of 35,474 individuals from 160 different organizations (Denison et al., 2006, p. 10). The proposed model was established to give an approach on how to measure organizational culture that influences the organizational effectiveness in general rather than the state of Agile in particular. However, by analyzing the survey's questionnaire in detail we found various questions with features of agility as defined by Beck (2001a and 2001b), Rigby et al. (2016) and Anghina et. al. (2018).

Krapf (2017, 2018, and 2019) developed a framework for the measurement of the level of organizational agility that positions culture in the center of the three pillars: Practices \& Methods, Structure \& Governance, and Values \& Competencies. Krapf (2018) argues that culture is a product of the three pillars and, hence, Agile culture can only be attained by taking measures in each of those three pillars. His Culture Check questionnaire encompasses six questions for each of the three dimensions evolving around the basic question on "how we do things around here" which he integrated into his Agile Business Consortium's Agile Culture Development Matrix (2019) at a later point in time. The matrix outlines different levels of agility proficiency (from surviving, stabilizing, secure, thriving to transformational) in different categories, such as, for example, on leadership, personal fulfilment, adaptability to change, innovation and learning, etc.

In summary, all presented frameworks deliver insights either into the assessment of organizational culture or its level of agility. But none of the frameworks assesses the culture's readiness for Agile by considering the organization's deeper cultural layer. Whereas the Denison model measures organizational culture that influences the organizational effectiveness, Krapf's Agile Culture Check, as well as his Agile Culture Development Matrix, assess the agility of a culture by looking at "how we do things around here", thus mainly focusing on the first two levels of corporate culture defined by Schein (2004): Artefacts and Espoused Beliefs and Values, while leaving Underlying Assumptions aside. As mentioned above, challenging, or questioning an organization's Underlying Assumptions in most cases triggers anxiety and defensiveness among its stakeholders, which needs to be considered when trying to change the organizational culture and the organization.

\section{A FRAMEWORK FOR ASSESSING THE CULTURE'S READINESS FOR AGILE}

As previously indicated, none of the existing frameworks and models are suited for assessing the readiness of organizational culture for Agile and a new framework needs to be constructed. The new framework rests on the premise that the organizational culture has to be in line with any organizational change - this especially in the case of working Agile. The goal is to assess if and how much the existing organizational culture enables acquiring Agile characteristics. Our focus was the organization's Espoused 
Beliefs and Values as well as Underlying Assumptions, which especially in the case of the latter, according to Schein (2004), are shared implicitly and often subconsciously, and thus stay hidden and are difficult to change. For that reason, the assessment did not include any structures, processes, methods, or other artefacts, that are visible and easily changeable.

Based on an extensive literature review of the Agile organization and organizational culture as well as the respective assessment models, a framework and a diagnostic instrument in a questionnaire-form were developed and tested in a pilot survey. Our research has been conducted in four phases: First, the structure of the framework was defined. Second, a new questionnaire was developed. Third, a pilot survey was conducted to test the new framework and to identify areas for improvement. Fourth, the test results were discussed with experts as well as with the test subjects to get a clearer understanding of the test results.

\section{New Framework Structure}

The starting point for the structure is the Five Trademarks of Agile Organizations, as defined by Anghina et al. (2018). The measurement of culture's readiness will be conducted around the categories of strategy, structure, people, and processes. To ensure a comprehensive and exhaustive measurement of the categories, they are split into two to three indexes, that were identified by analyzing the description of each category (see Table 2). The indexes measure how much the culture enables their respective trademark.

TABLE 2

\section{STRUCTURE OF THE FRAMEWORK TO ASSESS ORGANIZATIONAL CULTURE'S READINESS FOR AGILE}

\begin{tabular}{|l|l|}
\hline Category & Indexes \\
\hline \multirow{3}{*}{$\begin{array}{l}\text { Strategy } \\
\text { North Star Embodied Across the Organization }\end{array}$} & Shared Purpose and Vision \\
\cline { 2 - 2 } & Strategic Guidance \\
\cline { 2 - 2 } $\begin{array}{l}\text { Structure } \\
\text { Network of Empowered Teams }\end{array}$ & Sensing and Seizing Opportunities \\
\cline { 2 - 2 } & Team Level \\
\cline { 2 - 2 } $\begin{array}{l}\text { Process } \\
\text { Rapid Decision and Learning Cycles }\end{array}$ & Environment \\
\hline \multirow{3}{*}{$\begin{array}{l}\text { People } \\
\text { Dynamic People Model that Ignited Passion }\end{array}$} & Decision-Making \\
\cline { 2 - 2 } & Continuous Learning \\
\cline { 2 - 2 } & Transparency \\
\hline Technology & Involvement \\
\cline { 2 - 2 } Next-Generation Enabling Technology & Leadership \\
\cline { 2 - 2 } & Evolving Technology \\
\cline { 2 - 2 } & Next-Generation Technology \\
\hline
\end{tabular}

Source: Own illustration

\section{Development of a New Questionnaire}

After having established the structure and focal points of the framework, a new questionnaire was developed in a process of five steps:

In a first step, the questionnaires of pre-existing frameworks have been analyzed to ensure that the newly developed questionnaire includes all relevant aspects of organizational culture and Agile. The questionnaire of Denison's Model for Diagnosing Organizational Culture (60 questions, marked with A in the following methodological steps, also visualized in Figure 1) was chosen due to its strong focus on 
assessing organizational culture that influences the organizational effectiveness. The questionnaires of Joël Krapf's Agile Culture Check (18 questions, marked with B) and Agile Culture Development Matrix (7 questions on, marked with $C$ ) were chosen due to their strong focus on Agile organizational culture. From the last model, only questions on the Transformational level were taken, as this is the targeted level for Agile.

In a second step, each question was analyzed to assess, if it is Agile-specific, meaning it is relevant for the agility of an organization. This analysis was conducted by enquiring if the question relates to the four values or twelve principles of Agile (Beck, 2001a and 2001b). If not, the question was not pursued further. In total, 85 questions have been analyzed, 66 have been specified as being Agile-specific. Additionally, every question was labelled with one or more keywords to point out what subject of the question is about, which resulted in a total of 19 keyword categories. The categories and questions with the marking of the respective pre-existing framework can be seen on the right side of Figure 1.

In a third step, each keyword was then assigned to one or more trademarks of the new framework's structure, resulting in a map as shown in Figure 1. All pre-existing questions that have been already organized in categories were allocated to their respective trademarks.

In a fourth step, the new questionnaire questions were reformulated based on Rising's Agile Mindset, as the focus of the assessment lies on Edgar Schein's second and third cultural levels of Espoused Beliefs and Values as well as Underlying Assumptions.

The questions were posed as statements that the participants can then answer along a Likert scale ranging from strongly disagree (1) to strongly agree (7). In addition, reversed statements were implemented and stated in a way that legitimizes the less Agile-desirable responses. This method should reduce social responsibility bias (Krosnick \& Presser, 2010, p. 287). In normal statements, the Agile-desirable response is Strongly agree, and in reversed statements, it is Strongly disagree. The number of normal and reversed statements were kept at an equal level, to not have a specific focus on either of them.

In a fifth step, a new order of the questions was defined, and the final questionnaire set. When beliefs, values, and assumptions of a person are assessed, the order of posed questions plays a key role. As the new questionnaire also includes reversely-stated questions, it is important that the participants cannot make the connection to previous answers and are not influenced in replying other questions. Therefore, the order in which the questions are posed cannot represent the structure of the framework. According to Krosnick and Presser (2010), the easy and pleasant questions to answer should come in the beginning. Additionally, the first questions should address the subject of the questionnaire to make a connection between the accompanying description of the survey and the questionnaire itself. Afterward, more sensitive, and personal topics can be addressed (Krosnick \& Presser, 2010). For this reason, the first part of the questions was about general opinions of organizational culture. The more sensitive topics concerning personal attitudes and preferences were posed in the second part.

In summary, the new questionnaire consists of 45 statements worded to provide insights into the people's values, beliefs, and assumptions in an organizational culture structured around the five trademarks of an Agile organization. Four trademarks have 10 questions, and the trademark "Technology" five due to its limited size. To enable a natural weighting within each trademark, no specific number of questions per index was defined. The only restriction given is that each index should include at least two questions.

\section{Pilot Survey}

A pilot survey was conducted with the employees of five different organizations in Switzerland. One of the five organizations is used as the non-Agile benchmark, whereas the other four organizations provide data as Agile examples. The selection of the organizations was conducted with the purposive sampling technique.

For the Agile examples, it was ensured that various industries were included. The first Agile example was the IT department of an international insurance company that has been working with Agile methods for almost ten years. The second Agile example were multiple departments (IT, HR, and Operations) of a postal service organization which are known to work with Agile for around two years. The third example was a small consultancy specializing in an Agile culture establishment, founded three years ago. The fourth 
and last Agile example was the innovation platform of a soft drink producer, that was established around two years ago with the goal to develop new drinks and business models to keep up with evolving customer trends. The last two examples are considered to work Agile from the onset.

\section{FIGURE 1 \\ MAP OF CATEGORIES AND QUESTIONS ASSIGNED TO THE FRAMEWORK'S STRUCTURE}

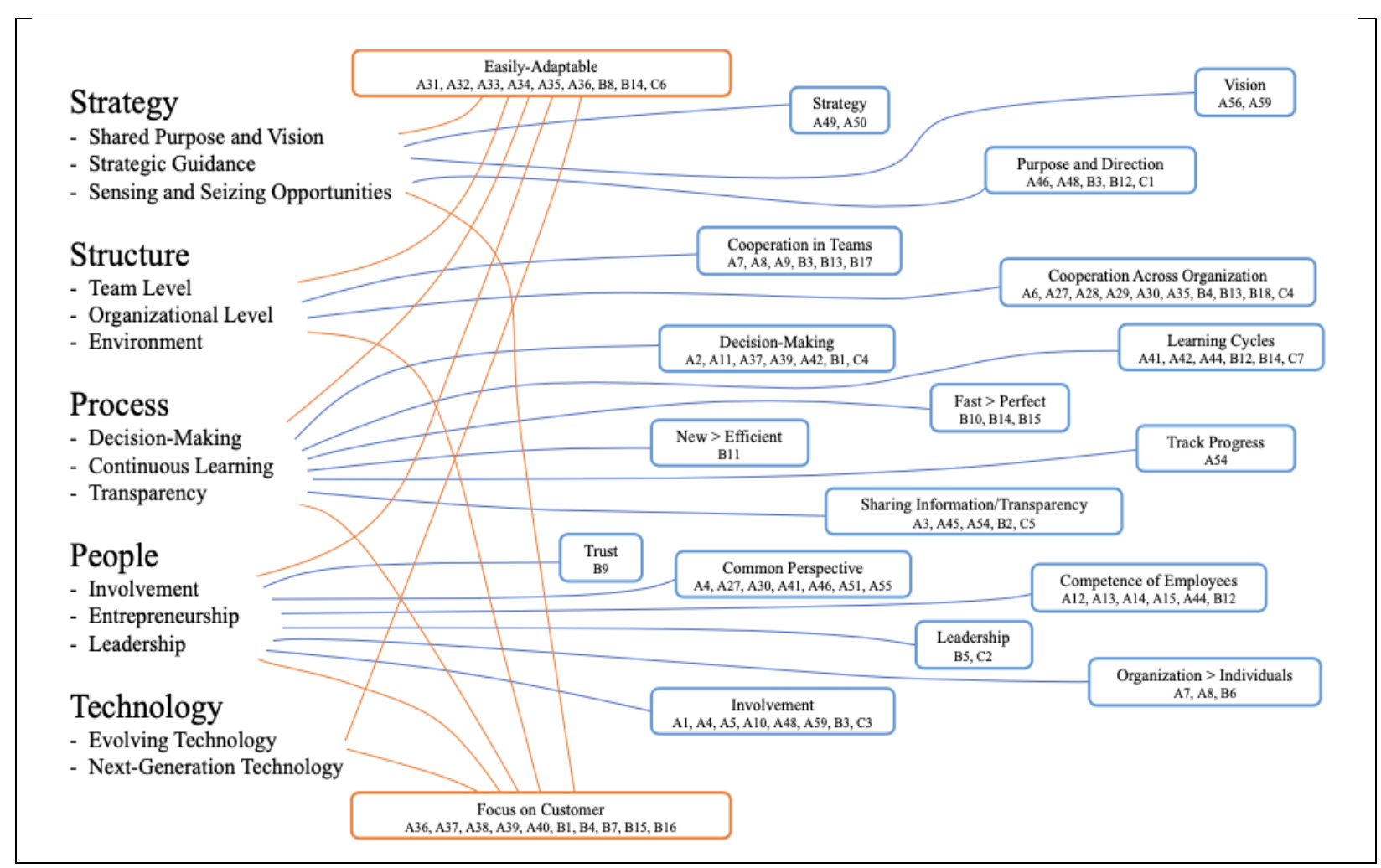

Source: Own illustration

For the non-Agile benchmark, state's tax administrations were selected as they are heavily guidelineoriented, include a lot of routine-based work, do not need to attract customers, and their primary service, collecting taxes, is mainly unaffected by disruptive changes in market, regulation, and technology so far, all conditions which are unfavorable for Agile (Rigby et al., 2016).

All organizations were tested with employees in Switzerland to ensure the accessibility and reduce societal cultural influences in the answering of the questionnaire thus ensuring the comparability of the results. The data for the testing was collected with an electronic-based questionnaire. In total, 179 responses were collected. 113 of non-Agile organizations and 66 of Agile organizations. Nine data sets were excluded due to incomplete records or wrong participation. In summary, a total of 125 complete and accurate data sets were analyzed: 63 in the non-Agile organization and 62 in the four Agile organizations (Insurance $n=36$, Postal Service $n=16$, Consultancy $n=6$, Soft Drinks Producer $n=4$ ).

The data was analyzed in two steps. First, the mean was selected to calculate the average responses. Second, they were measured with a rating from $0-100 \%$ according to how desirable they are for Agile, $0 \%$ being the lowest possible rating that expresses strictly no Agile-readiness whatsoever and $100 \%$ being the highest possible rating that expresses the perfect Agile-readiness. The readiness for Agile was presented linearly; each percentage point higher equals a slightly increased readiness for Agile. A reference point of $70 \%$ was defined as the threshold for an organizations' culture to be Agile-ready. In this paper, everything 
below $70 \%$ is considered not Agile-ready and everything above $80 \%$ as clearly Agile-ready. Ratings between $70-80 \%$ are considered as on the verge of being Agile-ready.

\section{RESULTS}

The calculated ratings for all five organizations are presented in Table 3 and explained below.

\section{TABLE 3 \\ RESULTS - RATINGS OF TRADEMARKS AND INDEXES OF THE FIVE TESTED ORGANIZATIONS}

\begin{tabular}{|c|c|c|c|c|c|}
\hline & $\begin{array}{l}\text { (Non-Agile) Tax } \\
\text { Administrations }\end{array}$ & Insurance & Postal Service & Consultancy & $\begin{array}{r}\text { Soft Drink } \\
\text { Producer }\end{array}$ \\
\hline Strategy & $67 \%$ & $71 \%$ & $75 \%$ & $74 \%$ & $76 \%$ \\
\hline Shared Purpose and Vision & $77 \%$ & $71 \%$ & $77 \%$ & $78 \%$ & $77 \%$ \\
\hline Strategic Guidance & $76 \%$ & $66 \%$ & $69 \%$ & $82 \%$ & $75 \%$ \\
\hline Sensing and Seizing Opportunities & $52 \%$ & $73 \%$ & $75 \%$ & $67 \%$ & $76 \%$ \\
\hline Structure & $53 \%$ & $75 \%$ & $79 \%$ & $75 \%$ & $71 \%$ \\
\hline Team Level & $59 \%$ & $80 \%$ & $82 \%$ & $79 \%$ & $80 \%$ \\
\hline Organizational Level & $62 \%$ & $75 \%$ & $77 \%$ & $79 \%$ & $75 \%$ \\
\hline Environment & $22 \%$ & $67 \%$ & $83 \%$ & $62 \%$ & $47 \%$ \\
\hline Process & $\mathbf{5 7} \%$ & $70 \%$ & $72 \%$ & $79 \%$ & $77 \%$ \\
\hline Decision-Making & $55 \%$ & $80 \%$ & $79 \%$ & $86 \%$ & $67 \%$ \\
\hline Continuous Learning & $49 \%$ & $57 \%$ & $60 \%$ & $69 \%$ & $84 \%$ \\
\hline Transparency & $80 \%$ & $86 \%$ & $91 \%$ & $90 \%$ & $76 \%$ \\
\hline People & $76 \%$ & $77 \%$ & $80 \%$ & $82 \%$ & $80 \%$ \\
\hline Involvement & $81 \%$ & $65 \%$ & $76 \%$ & $78 \%$ & $83 \%$ \\
\hline Entrepreneurship & $70 \%$ & $74 \%$ & $69 \%$ & $72 \%$ & $72 \%$ \\
\hline Leadership & $78 \%$ & $89 \%$ & $92 \%$ & $92 \%$ & $85 \%$ \\
\hline Technology & $74 \%$ & $81 \%$ & $82 \%$ & $76 \%$ & $83 \%$ \\
\hline Evolving Technology & $77 \%$ & $87 \%$ & $81 \%$ & $76 \%$ & $79 \%$ \\
\hline Next-Generation Technology & $71 \%$ & $78 \%$ & $82 \%$ & $76 \%$ & $85 \%$ \\
\hline
\end{tabular}

Source: Authors' own illustration

\section{Tax Administration}

For the tax administration, it is apparent that there is no clear differentiation between Agile and nonAgile on the two indexes of the trademark Strategy - Shared Purpose and Vision (77\%) and Strategic Guidance (76\%). The trademark Strategy scores as a whole lower than the threshold because of the index Sensing and Seizing Opportunities (52\%). The participants are undecided whether they want to work more closely with customers and other stakeholders (57\%). They value internal guidelines more than customers' ideas showing a lack of customer centricity and therefore missing readiness for Agile $(31 \%$, reversed question).

On two dimensions, the tax administration, however, clearly scored below the threshold: Structure (53\%) and Process (57\%). In the trademark Structure the tax experts are undecided on the topic of selforganizing teams $(52 \%)$, strongly dislike transparency and flexibility of working space and time (18\%) and 
prefer a clear work- and private-life separation and an unchangeable environment ( $26 \%$, reversed question). As a transparent and flexible environment is vital for working Agile, the organizational culture is not ready for Agile structures. In the trademark Process, the tax experts describe themselves as perfectionists (27\%, reversed question) and prefer not to make any mistakes even at the expense of efficiency (49\%). These answers show clear barriers for fast decision-making and continuous learning, demonstrating that the culture is not ready for Agile.

Two trademarks are on the verge of being ready for Agile - People (76\%) and Technology (74\%). For the first trademark, exceptionally high are the involvement $(85 \%)$ and the trust in the idea that leaders should be supportive, selfless coaches (87\%), but at the same time, an important task of leaders is to exercise control over the finished work (51\%). In the second trademark, the participants are convinced that new technology is key for competitiveness $(88 \%$ and $81 \%)$. Still a distrust in updates and new software is embedded in the organizational culture (67\% and 59\%, reversed questions).

\section{IT Department of an Insurance Company}

The results reveal that the organizational culture of the IT departments of the insurance company might be on the verge of being Agile-ready in Strategy (71\%), Structure (75\%), Process (70\%), and People (77\%). Nevertheless, as the organization works ten years with Agile methods already, a better result could have been expected. In the trademark Strategy, lower excitement, and motivation by the organizational vision $(66 \%)$ and undecided answers on the shared purpose $(56 \%)$ and suitability of the strategy as personal guidance (58\%) are the reason for the low rating. Regarding Structure, there is great interest in working in self-organized teams $(80 \%)$, but flexible and transparent working conditions were not seen as the preferred way of working even though it is vital for Agile (59\%). The trademark Process performs at the threshold, with very high customer centricity $(89 \%)$ and lower ratings on fast decision-making $(71 \%)$, and lower preference for fast and inexact work (37\% and 34\%, reversed questions). The trademark People shows a similar picture: While they value overall success higher than individual success (91\%), as well as Agile leadership (81\%), they do not seem to be highly involved with their work (58\%) and are undecided if they feel fulfilled after a day at work (61\%). The trademark that can clearly be considered Agile-ready is Technology (81\%) with strong agreement among the IT specialists that new technologies are needed (92\%) and that they bring more advantages than disadvantages $(82 \%)$.

\section{Postal Service}

The organization culture of the postal service might be on the verge of being Agile-ready in Strategy (75\%), Structure (79\%), and Process (72\%). In the trademark Strategy, the people of the organization like the organization's purpose ( $82 \%$ ) but feel only somewhat guided by its strategy (64\%). Although they value customer-centricity higher than internal guidelines $(82 \%)$, they still need to understand customer needs better (68\%). The trademark Structure shows strong preference for self-organizing teams $(83 \%)$, constantly improving collaboration in the organization (95\%), and flexible working conditions $(83 \%)$ are preferred. Still the participants are undecided about the challenges of working across departments and teams (47\%). The low agility level in the dimension Process is due to the indecisiveness if working slower and exact is better than faster and potentially less exact (50\%), and to the fact that many people see themselves as perfectionists (37\%, reversed question). On the other side, they completely agree on the need for transparency in the organization that enables effective Agile working $(90 \%)$.

The trademarks People (80\%) and Technology (82\%) are considered to be Agile-ready. Exceptionally high ratings regarding Agile leadership (94\%, 88\% and 91\%) are moderated by a lower rating in the index Entrepreneurship, indicating initial difficulties in tackling new challenges (60\%, reversed question). The importance of new technology is widely accepted (85\%).

\section{Consultancy}

The organizational culture of the consultancy is detected to be on the verge of Agile-ready in Strategy (74\%), Structure (75\%), Process (79\%), and Technology (76\%). The lowest score of the trademark Strategy is due to the low customer-centricity expressed in the index Sensing and Seizing Opportunities. The 
participants were undecided whether customer's feedback is feasible (58\%, reversed question) and did not clearly enough prefer customer wants before internal guidelines (67\%, reversed question). In Structure, high acceptance for self-organizing teams (100\%) and not hierarchical structures (86\%) meets indecisiveness about which way of working is better, alone or in a team (58\%). Similarly, flexible, and transparent working conditions were not preferred (50\%). While the indexes Decision-Making and Transparency in the trademark Process are clearly Agile ready $(97 \%, 94 \%)$, the participants are undecided if it is best to work slow and exact or fast and inexact (58\%, reversed question) and if they are perfectionists (56\%, reversed question). The trademark Technology shows that though implementing new technologies is primarily seen as necessary for advancements (87\%), a slight skepticism accompanies the implementation of new software $(70 \%)$.

The trademark People (82\%) can clearly be considered Agile-ready with high involvement $(90 \%)$ and a shared idea on Agile leadership (97\%, and 94\% reversed question). Still, sometimes, they do not see how their own goals are related to achieving the goals of the organization $(72 \%)$.

\section{Innovation Platform of a Soft Drink Producer}

The organizational culture of the soft drinks producer's innovation platform might be on the verge of being Agile-ready in Strategy (76\%), Structure (71\%), and Process (77\%). In the trademark Strategy, exceptionally high importance of customer wants $(100 \%)$ collides with a lower wish to work more closely with customers $(67 \%)$. The relatively low rating of Structure is due to undecided answers regarding flexible working conditions (50\%). Process shows high customer-centricity (83\%) and innovation (89\%). The participants do not see themselves as perfectionists (79\%, reverse question), but strongly disagree that fast, but not to $100 \%$ correct decisions are preferable $(33 \%)$.

The trademarks that clearly can be considered Agile-ready are People (80\%) and Technology (83\%). In the trademark People, high involvement in the organization $(83 \%)$, clear focus on the overall success $(89 \%)$ and shared idea of Agile leadership (88\%) are moderated by undecided answers concerning initial difficulties by new challenges $(50 \%)$. Technology is perceived to bring more improvements than problems $(83 \%)$ and there is no skepticism about its utility $(83 \%)$.

\section{DISCUSSION AND CONCLUSION}

\section{Theoretical Contributions}

The aim of this paper was to find out how companies can assess their organizational culture's readiness for Agile. We answered the research questions by developing a framework that can be used as a diagnostic tool to assess organizational culture's readiness for Agile.

Despite the extensive body of literature on the organizational agility, there are still few studies that focus on the role of organizational culture in Agile organizations and transformations. Furthermore, no existing framework was able to assess the agility of an organizational culture before implementing any Agile approaches. Additionally, no framework analyses the cultural beliefs, values, and subconscious underlying assumptions, which are difficult to grasp, access, and change.

By combining established models of organizational culture with the most recent knowledge about Agile organization, we developed a novel framework that allows the assessment of organizational culture's readiness for Agile. This framework was then tested with four Agile organizations operating in various industries and one non-Agile example that is used as a benchmark. In our inquiry, we focused on people's values, beliefs, and their underlying, often subconscious assumptions, while ignoring organizational artefacts (e.g., implemented structures, processes, practices, methods). The results demonstrated that the framework can assess the deeper layers of people's alignment with Agile, and therefore, assess the readiness of organizational culture for Agile.

The diagnostic tool revealed a clear difference between Agile and non-Agile organizations and on what might be important for Agile readiness. In addition, a possible rank of importance concerning the trademarks and indexes were derived. The results indicated that the trademarks Structure and Process constitute the most crucial focal points when it comes to Agile transformation. Structure refers to the 
organization that consists of specialized and empowered self-organizing teams, which collaborate across the whole organization under a flexible and transparent work environment. The trademark Process refers to the implementation of rapid cycles of thinking and doing, enabled by stakeholder involvement, ability to learn and constantly improve skills and full transparency of information. Additionally, specific indexes have been shown to exhibit a high discrepancy between non-Agile and Agile organizations: Team Level, Organizational Level and Environment (all integrated in the trademark Structure), Decision-Making and Continuous Learning (trademark Process) as well as Seizing and Sensing Opportunities (trademark Strategy). The last index describes the ability of employees to identify changes in customer needs and react to them quickly.

\section{Limitations and Recommendations for Further Research}

Because of the low response rates of certain organizations, the application of statistical methods was limited, and the results cannot be considered representative. For example, in the insurance company's IT department, a total of 36 responses were gathered from 200 employees. In the case of the soft drink producer's innovation platform, a total of four data sets were analyzed. Even though the response rate was high due to its small size of six employees, four data sets cannot precisely cover a rating from $0-100 \%$ in terms of Agile readiness, and therefore do not allow a reliable comparison between the Agile organizations. Because of the limited data set a calculation of the standard deviation in the trademarks and indexes and across the organizations does not deliver conclusive results. Furthermore, future research could target the internal validity and strength of the framework by studying the alignment and mutual interdependencies among the five trademarks. Relevant factor analysis requires data from a larger sample, such as over 500 participants, during the same time period (Nold et. al, 2018).

The analyzed organizations have a history of working Agile for two to ten years. For some of the organizations, the Agile approach has been implemented in only one or in a limited number of departments. Therefore, the organizations as a whole, are still in the transformation phase to become Agile and are not perfect examples for Agile. It is recommended to repeat the testing with whole organizations that work Agile for a longer time. This, with a higher number of employees and a higher response rate. A comparison between non-Agile, Agile in transformation and Agile can further validate and develop the framework and deliver insights on the phases of the organizational culture establishment and development in Agile organizations. In addition, the testing can be improved by assessing multiple departments of one organization. That would allow analysis of differences within one organizational culture.

The framework was developed to measure the readiness for Agile, based on people's values, beliefs, and assumptions. As those are unobservable variables, they were assessed by a questionnaire providing several statements that the participants then either agreed or disagreed with. The questions were developed with the aim to minimize the risk of collecting inaccurate answers due to inherent biases (e.g., social desirability bias, self-perception). Still, after the testing, some questions were identified that might have collected inaccurate answers. For further research, it is recommended to rephrase those specific questions to allow collecting answers of higher accuracy.

Finally, the average answer per question was calculated with the mean. This approach was chosen as authors commonly use the mean for Likert scales in practice, the extensive seven-point Likert scale resembles interval variables, and to establish a rating from $0-100 \%$, the mean provides a robust and easy way to understand foundation. Nevertheless, many researchers see Likert scales as ordinal variables and therefore, should be measured with the median or mode. If the objective of the research is not to establish a rating but to analyses each question separately, it is suggested, to use the median or mode for the calculation of the average answer per question. Furthermore, especially for organizations of smaller size, the median would allow an analysis free of outliers and therefore deliver more accurate results.

\section{Practical Implications}

With the growing number of companies implementing Agile transformation the focus on organizational culture role is increasing. The framework presented in this study can offer feedback on where and how much an organizational culture is ready for Agile. Due to its strict focus on assessing values, beliefs, and 
assumptions, and the exclusion of artefacts, the questionnaire can be used in teams and departments of any size, and in organizations operating in any industry.

For organizations that want to become Agile, the framework provides valuable information about the crucial focal points the organization has to pay attention to before it decides to change to Agile. It is suitable also for organizations that already work Agile but did not achieve the intended goals and impact. The results provide information on possible reasons for not meeting the objectives and identifies cultural deficiencies. Even organizations that transformed themselves successfully can use this tool to get a better understanding of their culture, find areas for further improvement, and therefore become even more Agile.

We recommended businesses to follow a two-step approach. First, to examine the culture's readiness for Agile in all relevant teams/departments that are in question to work Agile. Second, after identifying the problem areas, to introduce measures for gradually changing the culture in these areas. It is important to mention that receiving an unsatisfactory result on specific trademarks does not mean an organization cannot start its Agile transformation. It is suggested to then focus on those areas specifically, during the transformation to eliminate the deficiencies and increase the chances of a successful adoption.

We are convinced that the framework presented in this paper provides practitioners with helpful data that allows them to understand their culture's values, beliefs, and underlying assumptions. It raises awareness of the cultural aspect, which is essential for successful organizations, and can be used as a compass on their path to become and maintain Agile.

\section{REFERENCES}

Aghina, W., De Smet, A., \& Weerda, K. (2015). Agility: It Rhymes with Stability. McKinsey \& Company. Retrieved from https://www.mckinsey.com/business-functions/organization/our-insights/agilityit-rhymes-with-stability

Aghina, W., Ahlback, K., De Smet, A., Lackey, G., Lurie, M., Murarka, M., \& Handscomb, C. (2018). The Five Trademarks of Agile Organizations. McKinsey \& Company. Retrieved from https://www.mckinsey.com/business-functions/organization/our-insights/the-five- trademarks-ofagile-organizations

Agile Business Consortium Ltd. (2017). Towards an Agile Culture. Retrieved from https://cdn.ymaws.com/www.agilebusiness.org/resource/resmgr/documents/whitepaper/towards_ an_agile_culture.pdf

Agile Business Consortium Ltd. (2018). Agile Culture. Retrieved from https://www.agilebusiness.org/agile-culture

Bazigos, M., De Smet, A., \& Gagnon, C. (2015). Why Agility Pays. McKinsey \& Company. Retrieved from https:/www.mckinsey.com/business-functions/organization/our-insights/why- agility-pays

Beck, K., Beedle, M., van Bennekum, A., Cockburn, A., Cunningham, W., Fowler, M., \& Thomas, D. (2001a). Manifesto for Agile Software Development. Retrieved from http://agilemanifesto.org/

Beck, K., Beedle, M., van Bennekum, A., Cockburn, A., Cunningham, W., Fowler, M., \& Thomas, D. (2001b). Principles Behind the Agile Manifesto. Retrieved from $\mathrm{https}$ ///agilemanifesto.org/principles.html

Cameron, K., \& Quinn, R. (2006). Diagnosing and Changing Organizational Culture: Based on the Competing Values Framework (Revised Edition). Retrieved from https://zodml.org/sites/default/files/Diagnosing_and_Changing_Organizational_C ulture_Based_on_the_Competing_Values_Framework_\%28The_JosseyBass_Business_\%26_Management_Series\%29.pdf

Cameron, K. (2015). An Introduction to the Competing Values Framework. Retrieved from https://www.thercfgroup.com/files/resources/an_introduction_to_the_competing_values_framew ork.pdf

Campbell, J.P., Bownas, D.A., Peterson, N.G., \& Dunnette, M.D. (1974). The Measurement of Organizational Effectiveness: A Review of Relevant Research and Opinion. Navy Personnel 
Research and Development Center, Technical Report 75-1, San Diego, CA. https://doi.org/10.21236/AD0786462

CollabNet VersionOne. (2019). $13^{\text {th }}$ Annual State of Agile Report. CollabNet, Inc. Retrieved from https://explore.versionone.com/state-of-agile/13th-annual-state-of-agile-report

Darino, L., Sieberer, M., Vos, A., \& Williams, O. (2019). Performance Management in Agile Organizations. McKinsey \& Company. Retrieved from https:/www.mckinsey.com/businessfunctions/organization/our-insights/performance-management-in-agile-organizations

Denison, D., Janovics, J., Young, J., \& Cho, H.J. (2006). Diagnosing Organisational Cultures: Validating a Model and Method. Retrieved from https://www.researchgate.net/publication/228801211_Diagnosing_organizational_cultures_Valid ating a model and method

Denning, S. (2016) What Is Agile? Forbes. Retrieved from https://www.forbes.com/sites/stevedenning/2016/08/13/what-is-agile/

Dyer, L., \& Schafer, R.A. (2003). Dynamic Organizations: Achieving marketplace and organizational agility with people. CAHRS Working Paper 03-04. Ithaca, NY: Cornell University, School of Industrial and Labor relations, Center for Advanced Human Resource Studies. Retrieved from http://digitalcommons.ilr.cornell.edu/cahrswp/27/

Dweck, C. (2007). Mindset: The New Psychology of Success. New York: Ballantine Books.

Groysberg, B., Lee, J., Price, J., \& Cheng, J.Y-J. (2018, January/February). The Leader's Guide to Corporate Culture. Harvard Business Review, 160.

Handscomb, C., Jaenicke, A., Kaur, K., Vasquez-McCall, B., \& Zaidi, A. (2018). How to Mess Up Your Agile Transformation in Seven Easy (Mis)steps. McKinsey \& Company. Retrieved from https://www.mckinsey.com/business-functions/organization/our-insights/how-to- mess-up-youragile-transformation-in-seven-easy-missteps

Hemerling, J., Dosik, D., \& Rizvi, S. (2015). A Leader's Guide to “Always-On” Transformation. Boston Consulting Group. Retrieved from https://www.bcg.com/en-ch/publications/2015/peopleorganization-leaders-guide-to-always-on-transformation.aspx

Hofstede, G. (2003). Culture's Consequences: Comparing Values, Behaviors, Institutions and Organizations Across Nations (2nd ed.). Thousand Oaks: Sage Publications.

Iivari, J., \& Iivari, N. (2010). Organizational Culture and the Deployment of Agile Methods: The Competing Values Model View. Agile Software Development, pp. 203-222. https://doi.org/10.1007/978-3-642-12575-1_10

Krapf, J. (2017). Agilität als Antwort auf die Digitale Transformation. Fachmagazin Für Digitalisierung in Der Lehre, 3, 32-33.

Krapf, J. (2018). A Framework for Organizational Agility. Retrieved from https://joelkrapf.com/2018/08/07/a-framework-for-organizational-agility/

Krapf, J. (2019). Learning Culture Development to Enhance the Agility of Organizations. [Dissertation, University of St. Gallen]. Retrieved from https://www1.unisg.ch/www/edis.nsf/SysLkpByIdentifier/4840/\$FILE/dis4840.pdf

Krosnick, J., \& Presser, S. (2010). Question and Questionnaire Design. Handbook of Survey Research (2nd ed., pp. 263-313). Retrieved from http://www.stanford.edu/dept/communication/faculty/ krosnick/docs/2010/2010\%20Handbook\%20of\%20Survey\%20Research.pdf

Küpper, S., Kuhrmann, M., Wiatrok, M., Andelfinger, U., \& Rausch, A. (2017). Is There a Blueprint for Building an Agile Culture? Gesellschaft für Informatik (GI) e.V. Retrieved from https://www.researchgate.net/profile/Marco_Kuhrmann/publication/318455594_Is_There_a_Blue print_for_Building_an_Agile_Culture/links/59802d3fa6fdcc1a9ad2b955/Is-There-a-Blueprintfor-Building-an-Agile-Culture.pdf

Lin, C., Chiu, H., \& Chu, P. (2006). Agility index in the supply chain. International Journal of Production Economics, 100(2), 285-299.

Linssen, D. (2017). Busting the Myth of The Lean Startup. Retrieved from https://medium.com/@edenspiekermann/busting-the-myth-of-the-lean-startup-64754d9a7e94 
Najrani, M. (2016). The Effect of Change Capability, Learning Capability and Shared Leadership on Organizational Agility. [Dissertation, Pepperdine University] Graduate School of Education and Psychology.

Nold, H., Anzengruber, J., Woelfle, M., \& Michel, L. (2018). Organizational Agility - Testing, Validity, and Reliability of a Diagnostic Instrument. Journal of Organizational Psychology, 18(3), 104117.

Plant, R., \& Murrell, S. (1997). The Agile Organization: Technology and Innovation. AAAI Technical Report WS-97-02; Retrieved from https://www.aaai.org/Papers/Workshops/1997/WS-9702/WS97-02-004.pdf

Quinn, R.E., \& Rohrbaugh, J. (1983). A Spatial Model of Effectiveness Criteria: Towards a Competing Values Approach to Organizational Analysis. Management Science, 29(3), 363-377.

Rigby, D.K., Sutherland, J., \& Takeuchi, H. (2016). Embracing Agile. Harvard Business Review. Retrieved from https://hbr.org/2016/05/embracing- agile

Rising, L. (2016). The Agile Mindset. European Testing Conference 2016, Bucharest, Romania. Retrieved from http://europeantestingconference.eu/slides16/ETC16_LindaRising.ppt

Rütti, N. (2018, December 5). Der Agile Mitarbeiter im Digitalen Strudel. Neue Zürcher Zeitung. Retrieved from https://www.nzz.ch/wirtschaft/der-agile-mitarbeiter-im-digitalen-strudelld. 1442307

Schein, E. (1985). Organizational Culture and Leadership. San Francisco: Jossey-Bass.

Schein, E. (1994). Innovative Cultures and Organizations. In T.J. Allen \& M.S. Scott Morton (Eds.), Information Technology and the Corporation of the 1990s: Research Studies (pp. 125-146). New York: Oxford University Press.

Schein, E. (2004). Organizational Culture and Leadership (3rd Ed.). Josey-Bass, San Francisco. Retrieved from http://gen.lib.rus.ec/book/index.php?md5=83A44B46498772FEE0D7B9E64F9E DD28

Sherehiy, B. (2007). A Review of Enterprise Agility: Concepts, Frameworks, and Attributes. International Journal of Industrial Economics, 37(5), 445-460.

Schwartz, T. (2018). Leaders Focus Too Much on Changing Policies, and Not Enough on Changing Minds. Harvard Business Review. Retrieved from https://hbr.org/2018/06/leaders-focus-toomuch-on-changing-policies-and-not- enough-on-changing-minds

Teece, D., Peteraf, M., \& Leih, S. (2016). Dynamic capabilities and organizational agility: Risk, uncertainty, and strategy in the innovation economy. California Management Review, 58(4), 1335. doi:10.1525/cmr.2016.58.4.13

Verdu, A., \& Gomez-Gras, J. (2009). Measuring the organizational responsiveness through managerial flexibility. Journal of Organizational Change Management, 22(6), 668-690.

Wessel, M. (2017, September 4). Why Preventing Disruption in 2017 Is Harder Than It Was When Christensen Coined the Term. Harvard Business Review. Retrieved from https://hbr.org/2017/09/why-preventing-disruption-in-2017-is-harder-than-it-was-whenchristensen-coined-the-term 